\title{
Food and beverage purchases in corner stores, gas-marts, pharmacies and dollar stores
}

\author{
Caitlin E Caspi ${ }^{1, *}$, Kathleen Lenk ${ }^{2}$, Jennifer E Pelletier ${ }^{2}$, Timothy L Barnes ${ }^{2}$, Lisa Harnack², \\ Darin J Erickson ${ }^{2}$ and Melissa N Laska ${ }^{2}$ \\ 'Department of Family Medicine and Community Health, Program in Health Disparities Research, University of \\ Minnesota, 717 Delaware Street SE, Minneapolis, MN 55414, USA: ${ }^{2}$ Division of Epidemiology and Community \\ Health, University of Minnesota, Minneapolis, MN, USA
}

Submitted 23 February 2016: Final revision received 18 July 2016: Accepted 27 July 2016: First published online 19 September 2016

\begin{abstract}
Objective: Little is known about customer purchases of foods and beverages from small and non-traditional food retailers (i.e. corner stores, gas-marts, dollar stores and pharmacies). The present study aimed to: (i) describe customer characteristics, shopping frequency and reasons for shopping at small and non-traditional food retailers; and (ii) describe food/beverage purchases and their nutritional quality, including differences across store type.

Design: Data were collected through customer intercept interviews. Nutritional quality of food/beverage purchases was analysed; a Healthy Eating Index-2010 (HEI-2010) score for purchases was created by aggregating participant purchases at each store.

Setting: Small and non-traditional food stores that were not WIC-authorized in Minneapolis and St. Paul, MN, USA.

Subjects: Customers ( $n$ 661) from 105 food retailers.

Results: Among participants, 29\% shopped at the store at least once daily; an additional $44 \%$ shopped there at least once weekly. Most participants (74\%) cited convenient location as the primary draw to the store. Customers purchased a median of $2262 \mathrm{~kJ}(540 \mathrm{kcal})$, which varied by store type $(P=0 \cdot 04)$. The amount of added sugar far surpassed national dietary recommendations. At dollar stores, participants purchased a median of $5302 \mathrm{~kJ}(1266 \mathrm{kcal})$ for a median value of \$US 2.89. Sugar-sweetened beverages were the most common purchase. The mean HEI-2010 score across all stores was 36.4.

Conclusions: Small and non-traditional food stores contribute to the urban food environment. Given the poor nutritional quality of purchases, findings support the need for interventions that address customer decision making in these stores.
\end{abstract}

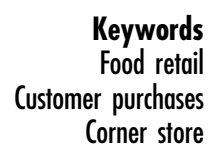

Keywords

Corner store
Small food retailers are a common source of food for urban residents in the $\mathrm{USA}^{(1)}$, particularly those living in low-income neighbourhoods ${ }^{(1-4)}$. Visits to small food stores (commonly referred to as 'corner stores') have been described as 'routinized' ${ }^{\text {(5) }}$, with customers often reporting that they visit these stores every day or multiple times per week $^{(6-11)}$. In general, corner stores stock few healthy options and an abundance of less healthy items like snacks, candy and sugar-sweetened beverages ${ }^{(2,12-14)}$. Purchases at corner stores tend to be energy-dense, low in nutritional quality and often include sugar-sweetened beverages and other less healthy products ${ }^{(1,6,9-11,15-17)}$. Frequently purchasing food from corner stores has been associated with poor health outcomes, such as increased obesity risk ${ }^{(18-20)}$.
In addition to corner stores, other types of businesses that have usually been considered non-food stores have recently begun to be recognized for their contribution to urban food environments, including gas-marts, pharmacies and dollar stores $^{(21-27)}$. Previous studies vary on the terminology used to describe such retailers, but we refer to these stores collectively as 'small and non-traditional food stores' herein.

Although the total share of food purchased at small and non-traditional stores in the USA is modest, there is considerable evidence of the growth of this food retail market in recent years ${ }^{(28-31)}$. A study by Stern et al. estimated that the proportion of food retail volume from convenience stores (including dollar stores and pharmacies) was about $6 \%$ of all food retail volume in 2012, an increase of $50 \%$ from $2000^{(27)}$. 
Small and non-traditional food stores often carry a substantial amount of foods and beverages with limited healthy options ${ }^{(21,23,24,32)}$. While recent Dietary Guidelines for Americans (2015-2020) specifically recommend limiting added sugar and saturated fats and choosing more nutrient-dense foods ${ }^{(33)}$, small and non-traditional stores may be unlikely to stock foods that are consistent with these recommendations. Stern et al. reported that, in 2012, purchases at convenience stores had the highest density of energy, sugar and saturated fat compared with other grocery store types ${ }^{(27)}$. Another study in the Twin Cities metropolitan area, Minnesota showed that gas-marts, pharmacies and dollar stores have very little fresh and frozen produce and few options for customers to buy wholegrain-rich products ${ }^{(24,25)}$.

The lack of healthy items in these retail settings is particularly noteworthy as these stores also frequently participate in federal food assistance programmes, like the Supplemental Nutrition Assistance Program (SNAP) ${ }^{(25)}$, and thus may serve as a source of staple foods for low-income families. According to a national report, it has been estimated that $36 \%$ of SNAP transactions occur outside supermarkets and supercentres ${ }^{(34)}$. In Minnesota, where SNAP transactions are similarly distributed across store type compared with nationally, the use of SNAP benefits at small and non-traditional stores may be even higher in certain neighbourhoods. A study in the Twin Cities metropolitan area showed that a far greater share of SNAP benefit redemptions occur outside supermarkets and supercentres in low-income and high-minority $\operatorname{areas}^{(35)}$.

Little is known about the nutritional quality of purchases in small and non-traditional food stores, or the characteristics of the customers who frequent such stores to buy food. As small businesses are increasingly a target of community food environment interventions ${ }^{(2,3,11,36-38)}$, it is necessary to recognize the range of stores that contribute to urban residents' diets and understand food purchasing patterns at these stores. Understanding purchases in small and non-traditional stores is also important because the 2014 Farm Bill will soon require SNAPauthorized stores to increase the number of varieties and food groups that they carry, including requiring them to stock more perishable items ${ }^{(39)}$. These changes are most likely to affect small and non-traditional food stores, as larger grocery stores likely already meet the proposed requirements. Thus, current circumstances require a better grasp of customer demand as these stores prepare to meet the new supply requirements, including an understanding of the characteristics of customers who shop in these stores, their frequency and reasons for shopping at these stores, the number and type of purchases made, the amount of money spent and the nutritional quality of the purchases.

Therefore, the purpose of the present study was to: (i) describe the characteristics of customers shopping at small and non-traditional food retailers (including corner stores, gas-marts, dollar stores, pharmacies) in the Twin Cities, MN, USA; and (ii) describe the foods and beverages purchased at these stores and their nutritional quality, including differences across store type.

\section{Methods}

\section{Store customer sample}

The present study was conducted as part of an evaluation of a city ordinance regulating minimum stocking requirements for food retailers outside the downtown core commercial districts in Minneapolis; the evaluation also included comparable stores in St. Paul (a control site). As of April 2015, the Minneapolis Staple Foods Ordinance ${ }^{(40)}$ required licensed grocery stores to stock a minimum amount and variety of specific food categories, including fruits and vegetables, whole grains and low-fat dairy. Data included in analyses presented herein are based only on baseline (pre-policy) data collected between July and November 2014. Participants were recruited as they exited eligible food stores within the city limits of Minneapolis and St. Paul, MN. Relevant licensing agencies provided a list of all stores with grocery licenses (i.e. the Minneapolis Health Department for Minneapolis stores and the Minnesota Department of Agriculture for St. Paul stores). In Minneapolis, this included all retail stores that sold food more than confectionery items (ready-to-eat, singleservice, pre-packaged snack items and beverages); in St. Paul, it included all retail food handlers that sell food directly to the ultimate consumer.

The Minneapolis Staple Foods Ordinance was designed to have a wide reach with the goal of improving healthy food access, acknowledging that it is difficult to find nutritious staple foods outside traditional grocery stores ${ }^{(40)}$. A small number of exemptions to the ordinance applied to stores that would not reasonably be expected to stock a minimal amount of foods, including small vendors in market areas (e.g. produce stands), liquor stores or specialty stores (e.g. spice shops). Stores located in the core downtown commercial district were also exempt. The purpose of the research team's evaluation was to examine the effects of the ordinance on stores that would likely be most impacted by the Minneapolis Staple Foods Ordinance. For this reason, supermarkets, mass merchandizers and stores that were listed in the state database as participating in the Special Supplemental Nutrition Program for Women, Infants, and Children (WIC; which must meet specific programme requirements for stocking healthy, staple foods) were excluded from the study sample, along with the stores exempt from the ordinance in Minneapolis and comparable stores in St. Paul. Also excluded from the evaluation study were stores that had invalid licensing addresses. In summary, both the ordinance and the evaluation targeted small and non-traditional food retailers that had reasonable 
potential to improve their supply of healthy foods to meet local minimum stocking requirements.

Out of 255 eligible stores, 180 were selected via a simple random sample to participate in the study and were visited by study staff for data collection. A simple random sample was conducted rather than a stratified sample by store type because the evaluation was designed to assess the overall impact of the ordinance outside traditional grocery stores, rather than the impact within each store type. Twenty of these stores were identified as ineligible upon visiting the store (e.g. due to new participation in WIC). In the eligible sample, all stores were categorized as a corner store (39\%), gas-mart (36\%), dollar store (9\%), pharmacy (14\%) or general retailer (1\%). Eight-six per cent of these stores accepted SNAP benefits.

In teams of two, data collectors obtained permission from a store employee to recruit customers exiting the store for intercept interviews. Thirty-two stores refused to participate. Gas-marts comprised most of the refusals ( $n$ 19), followed by corner stores ( $n 7$ ), dollar stores $(n$ ) and pharmacies ( $n$ 2). In twenty-two stores, no participants were successfully recruited. In the remaining 106 stores in which customer data were collected, 37\% were corner stores, 35\% were gas-marts, $8 \%$ were dollar stores, $19 \%$ were pharmacies and $1 \%$ were general retailers.

\section{Customer intercept interviews}

Data collectors attempted recruitment for $30 \mathrm{~min}$ at each store; if at least one survey was completed, they stayed an additional $15-30 \mathrm{~min}$. The target number of recruited participants at each store was at least five. Stores where one to four participants were recruited during a single visit were visited again on a different day to recruit additional participants. Eligible participants were English-speakers who were at least 18 years old and who made a food or beverage purchase at the store. After obtaining informed consent and verifying eligibility, data collectors recorded participants' food and beverage purchases (quantity, size, product name and price paid) and administered a brief survey. In total, 668 participants were recruited. The first fifty-two participants were recruited during a pilot phase to test the feasibility of the recruitment protocol. Following the pilot phase, the instrument was not changed, but the incentive for participation was increased to \$US 10 (from \$US 5). Data were collected between 09.00 and 18.00 hours on Monday through Friday, and between 11.00 and 19.00 hours on Saturday and Sunday.

Non-participation was tracked for individuals who exited the store but did not complete a survey. Data collectors recorded the reason for non-participation (e.g. ineligible reason or refused/no response) and the person's apparent gender and presumed race/ethnicity (White/ Caucasian, Black/African American, Asian, Hispanic, don't know). Individuals who ignored the data collector, but appeared to be eligible (e.g. an adult who exited carrying a store bag), were marked as refusals.
The overall participation rate was $35 \%$, with higher rates in corner stores (47\%) and dollar stores (46\%), and lower rates in gas-marts (32\%) and pharmacies (27\%). At all store types, participation was higher among Black/ African American customers compared with White customers. Overall, $53 \%$ of participants self-identified as White, compared with $61 \%$ of non-participants who were presumed to be White. In contrast, $40 \%$ of participants self-identified as Black/African American, compared with $28 \%$ of non-participants.

\section{Food and nutrient data}

Data on all food and beverage items purchased were entered by trained study staff into Nutrition Data System for Research (NDSR), a nutrient analysis program that generates values for 165 nutrients, nutrient ratios and other food components, and food servings for 166 food categories. To characterize food and beverage purchases, the food categories available in NDSR were collapsed into twenty-four mutually exclusive categories (seventeen food categories, seven beverage categories). Food categories included solid fruits; vegetables and legumes; grains and breads (e.g. bread, tortillas, crackers, pasta, rice, cereals); sweet baked goods (e.g. cakes, cookies, pastries); savoury snacks (e.g. snack chips, popcorn); cheese and yoghurt; ice cream and frozen desserts; red meat (e.g. beef, pork); processed meat (e.g. cured meats, cold cuts); poultry and fish; eggs; nuts, seeds and nut/seed butters; candy; fried fruits and vegetables; fats, sugars and condiments (e.g. oil, syrup, salad dressing); baby food; and miscellaneous foods (e.g. soup broth, sugar substitute). Beverage categories included sugar-sweetened beverages (e.g. soft drinks, fruit drinks, chocolate milk); artificially sweetened beverages (e.g. diet soft drinks); plain water; coffee, tea or other unsweetened beverages; $100 \%$ fruit and vegetable juices; unsweetened milk and milk substitutes (e.g. whole milk, soya milk); and alcoholic beverages. A comprehensive description of the food categories is available in the online supplementary material, Supplemental Table 1.

For each participant purchase, the total number of servings of each food/beverage category was calculated. If the total servings for a food category was $\geq 1$ (e.g. $\geq 1 / 2$ cup of fruits or vegetables, $\geq 8$ fluid ounces of soft drink), the participant was categorized as having purchased a serving or more of food in the category.

\section{Healthy Eating Index-2010 measure}

Using the food and nutrient data collected above, a Healthy Eating Index-2010 (HEI-2010) score was created by summing twelve sub-components to create a score with a range of $0-100^{(41)}$. The HEI-2010 is an updated version of the HEI-2005 ${ }^{(42)}$, a validated tool that was developed by the National Cancer Institute and the US Department of Agriculture (USDA) to measure the degree to which a diet or food source is consistent with federal dietary 
guidelines $^{(41)}$. The average HEI of total diet intake for the total US population is $59^{(43)}$. HEI-2010 scores are computed by deriving ratios of dietary constituents to energy, and then scoring each of the twelve subcomponents according to minimum and maximum standards outlined by the USDA ${ }^{(44)}$. Three sub-components (sodium, refined grains and empty calories) are reverse coded so that higher scores consistently represent a more balanced and healthful diet. The HEI has been used to assess components of the food environment ${ }^{(45-49)}$, grocery purchases $^{(50)}$ and dietary intake ${ }^{(51-53)}$. The HEI-2010 is calculated using nutrient density, so it can measure the diet quality of any amount or assortment of foods ${ }^{(49)}$. HEI-2010 scores for purchases were calculated at the store level by aggregating the items purchased by all study participants recruited at that store. Thus, the HEI-2010 measure reflected purchases made by a sample of participants (as opposed to all customers) and the healthfulness of those purchases (as opposed to the food supply). One of the strengths of the HEI-2010 is that it balances both the healthy and less healthy components of a mix of foods into a single summary score. For the purposes of the current analysis, store-level HEI-2010 scores were more informative than individual purchase HEI-2010 scores, as aggregating more items would reflect a range of foods and nutrients purchased at a store, rather than just the foods and nutrients purchased by one participant, which might only reflect one or two items.

\section{Participant characteristics, shopping behaviour and store type}

Data on participant demographics (age, gender, race/ ethnicity, education, employment), were obtained from the customer intercept survey. Shopping characteristics included the frequency with which each participant shopped at the store (at least once daily, one to six times weekly, once weekly or less), the primary reason they shopped at the store they were recruited from (close to home, close to work/other destination, know staff here, good service, good prices, good quality food, good selection of foods, it's clean, just passed by, other), the number of food or beverage items purchased and the dollar amount spent on foods and beverages. Other participant characteristics, including height and weight, were obtained from the customer intercept survey; BMI was calculated using self-reported heights and weights.

\section{Statistical analyses}

We first calculated descriptive statistics for all measures: participant characteristics, participant shopping behaviours, types of items purchased, and quantity, dollar value and nutritional quality of purchases. The unit of analysis was customer purchase event, except for HEI-2010 analyses which were conducted at the store level. For all measures, we calculated descriptive statistics across the full sample (all store types combined) and by each of the store types. Only one store was categorized as a general retailer (Kmart); given that the analysis was stratified by store type, this store (and the seven customers recruited there) was excluded from the analysis. Thus, the final analytic sample contained 105 stores and 661 customers. Nineteen participants were excluded from the HEI-2010 calculations because they did not purchase any energy-containing products (e.g. only water) and HEI-2010 calculations are based on energy density. Descriptive statistics included percentage of purchases for categorical variables, mean and standard deviation for continuous variables with normal distribution, and median, 25 th percentile and 75 th percentile for continuous variables that were skewed (i.e. not normally distributed). There was no conceptual basis for excluding outliers in our analysis, as the range of purchases in the sample reflects credible, real-world uses of the retailers in our sample, but by reporting medians we limited the influence of these data points. For comparisons by store type, we used various methods to test for statistically significant differences depending on measure: (i) $\chi^{2}$ (for categorical variables if all cells had expected frequency $\geq 5$ ); (ii) Fisher exact (for categorical variables if some cells had expected frequency <5); (iii) ANOVA (for means); and (iv) BrownMood (for medians; used due to unequal variance across store type). All analyses were conducted using the statistical software package SAS version 9.4.

\section{Results}

Participant characteristics and shopping behaviours are presented in Table 1 for the overall sample and by store type. The mean age was 40 (SD 15) years and $57 \%$ of participants were male. Mean BMI was 28 (SD 6) $\mathrm{kg} / \mathrm{m}^{2}$. The sample was $47 \%$ White non-Hispanic, 36\% Black non-Hispanic, and a small percentage Native American/ Alaska Native, Asian, Hispanic, multi-race or other (3-4\% each). Thirty-eight per cent had a high-school diploma or less, and most (64\%) were employed. Participant characteristics differed between store types for all variables except BMI. For example, a greater proportion of participants from gas-marts were male and/or employed, compared with those from other store types. A greater proportion of participants from dollar stores were nonHispanic Black and/or had a high-school education or less. A greater proportion of participants from pharmacies were non-Hispanic White and/or had a bachelor's degree or higher.

Most participants reported frequently shopping at the store from which they were recruited. On average, $29 \%$ of participants reported shopping at the store at least once daily (ranging from $11 \%$ at pharmacies to $38 \%$ at corner stores). An additional $44 \%$ of participants reported shopping there at least once weekly (ranging from $38 \%$ in 
Table 1 Participant characteristics and shopping behaviours among customers shopping at corner stores, gas-marts, dollar stores and pharmacies, Minneapolis and St. Paul, MN, USA, July-November 2014

\begin{tabular}{|c|c|c|c|c|c|c|}
\hline & $\begin{array}{l}\text { All stores } \\
(n \text { 661) }\end{array}$ & $\begin{array}{l}\text { Corner stores } \\
\quad(n 194)\end{array}$ & $\begin{array}{c}\text { Gas-mart } \\
(n 268)\end{array}$ & $\begin{array}{l}\text { Dollar store } \\
\quad(n \text { 67) }\end{array}$ & $\begin{array}{c}\text { Pharmacy } \\
(n 132)\end{array}$ & $P^{*}$ \\
\hline Age (years), mean & 40 & 38 & 40 & 44 & 42 & $<0.01$ \\
\hline SD & 15 & 13 & 15 & 15 & 17 & \\
\hline BMI $\left(\mathrm{kg} / \mathrm{m}^{2}\right)$, mean & 28 & 28 & 28 & 28 & 28 & 0.50 \\
\hline SD & 6 & 6 & 7 & 7 & 7 & \\
\hline Gender: male $(\%) \dagger$ & 57 & 56 & 63 & 48 & 48 & 0.01 \\
\hline Race/ethnicity (\%) & & & & & & $<0.01$ \\
\hline Hispanic & 3 & 4 & 4 & 3 & 2 & \\
\hline \multicolumn{7}{|l|}{ Non-Hispanic } \\
\hline White alone & 47 & 39 & 50 & 27 & 63 & \\
\hline Black alone & 36 & 43 & 31 & 50 & 29 & \\
\hline American Indian or Alaskan & 4 & 2 & 5 & 9 & 1 & \\
\hline \multicolumn{7}{|l|}{ Native alone } \\
\hline Asian alone & 3 & 7 & 2 & 3 & 2 & \\
\hline Other race alone & 4 & 2 & 5 & 5 & 3 & \\
\hline Multi-race & 3 & 4 & 4 & 3 & 1 & \\
\hline Education (\%) & & & & & & $<0.01$ \\
\hline High-school diploma or less & 38 & 40 & 40 & 52 & 21 & \\
\hline Some college & 37 & 32 & 34 & 37 & 49 & \\
\hline Bachelor's degree or higher & 26 & 27 & 26 & 10 & 30 & \\
\hline Employment (\%) & & & & & & $<0.01$ \\
\hline Employed & 64 & 60 & 71 & 51 & 60 & \\
\hline Unemployed/disability & 26 & 32 & 19 & 31 & 25 & \\
\hline Other (student, retired) & 11 & 7 & 10 & 18 & 15 & \\
\hline Frequency of shopping at the store & & & & & & $<0.01$ \\
\hline At least once daily & 29 & 38 & 30 & 33 & 11 & \\
\hline $1-6$ times weekly & 44 & 38 & 44 & 47 & 50 & \\
\hline Less than once weekly & 27 & 24 & 26 & 20 & 39 & \\
\hline Primary reason for shopping at the store & & & & & & $<0.01$ \\
\hline Close to home & 45 & 60 & 40 & 30 & 43 & \\
\hline Close to work/destination & 29 & 19 & 37 & 23 & 30 & \\
\hline Know staff here & 2 & 2 & 3 & 0 & 2 & \\
\hline Good service & 2 & 2 & 2 & 2 & 2 & \\
\hline Good prices & 6 & 1 & 3 & 39 & 6 & \\
\hline Good quality food & 2 & 5 & 1 & 0 & 0 & \\
\hline Good selection of foods & 2 & 5 & 1 & 3 & 2 & \\
\hline It's clean & 0.3 & 0 & 1 & 0 & 0 & \\
\hline Just passed by & 1 & 1 & 1 & 2 & 1 & \\
\hline Other & 9 & 7 & 11 & 2 & 14 & \\
\hline
\end{tabular}

*ANOVA test for age and $\mathrm{BMI} ; x^{2}$ test for gender, education and employment and frequency of shopping; Fisher test for race and reasons for shopping because one or more cells has expected frequency $<5 . P \leq 0.05$ indicated in bold font. $\dagger$ Frequencies may not add up to $100 \%$ due to rounding.

†Examples include: gas, availability of a specific item.

corner stores to $50 \%$ at pharmacies). At all store types, the majority of participants cited proximity to home, work or other destinations as the most important reason for shopping at the store. This ranged from $53 \%$ in dollar stores to $79 \%$ in corner stores. Only at dollar stores were good prices commonly cited as the most important reason for shopping at the store (39\%). Few participants reported reasons like staff, service, food quality, food selection or cleanliness as the primary draw to the store.

Purchasing patterns and nutrient information for purchases at each store type are presented in Table 2 . The median number of items purchased was 2 across all store types and the median amount spent was \$US 2.76. There was not a statistically significant difference by store type in the number of items purchased or the amount spent $(P=0.09)$.

Customers purchased a median of $2262 \mathrm{~kJ}(540 \mathrm{kcal})$ with a considerable range (25th-75th percentile $=$
$1058-5392 \mathrm{~kJ}(253-1287 \mathrm{kcal}))$. There were statistically significant differences in the amount of $\mathrm{kJ} / \mathrm{kcal}$ purchased by store type $(P=0.04)$. This difference was likely driven by dollar stores, where participants purchased a median of $5302 \mathrm{~kJ}(1266 \mathrm{kcal})$. Across all participants, the median percentage of energy from added sugars was 39\%, for saturated fat it was $6.2 \%$; and median $\mathrm{Na}$ values were $800 \mathrm{mg}$ per $4188 \mathrm{~kJ}$ (1000 kcal). Purchases from gas-marts had the highest percentage of energy from saturated fat $(9.4 \%)$, whereas corner store purchases had a median of $3.5 \%$.

Table 3 presents the percentage of participants who purchased one or more serving of various types of foods and beverages. Sixty-four per cent of participants purchased at least one serving of a food and $67 \%$ purchased at least one serving of a beverage. Nearly one-half of participants ( $46 \%$ ) purchased a sugar-sweetened beverage. The most common types of foods purchased 


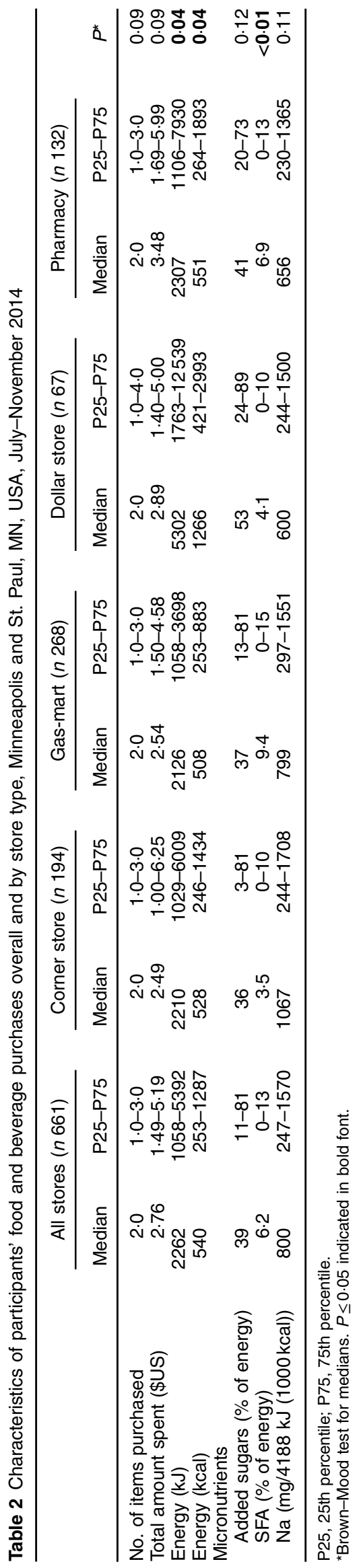

by participants were grains (18\% of participants purchased at least one serving of grains, such as cereal, bread or tortillas), savoury snacks (17\%), candy (15\%), sweet baked goods (13\%) and other fats, sugars and condiments (13\%). Two per cent of participants purchased at least one serving of fruit and $6 \%$ purchased at least one serving of vegetables. Overall, $5 \%$ of participants purchased bottled water. Purchases of other staple food and beverage items (e.g. eggs, cheese/yoghurt, milk, 100\% juice, poultry/fish and nuts/nut butter) were uncommon ( $\leq 5 \%$ for each category).

Differences in purchases across store type were evident for sugar-sweetened beverages $(P=0 \cdot 03)$, which were the highest in dollar stores (58\%) and the lowest in pharmacies $(35 \%)$. Purchases of candy $(P<0 \cdot 01)$ also differed by store type, with participants at dollar stores and pharmacies more than three times as likely to purchase candy than participants in corner stores (28\%v. 9\%).

HEI-2010 scores for purchases averaged $36 \cdot 4$, with no statistically significant difference in HEI-2010 across store type (see Table 4). There were also no statistically significant differences across store type in any of the twelve HEI-2010 sub-components. Scores were lowest on greens and beans and whole fruit $(<5 \%$ of the maximum score). Scores were highest on sodium and refined grains ( $>70 \%$ of the maximum score).

\section{Discussion}

The present study is part of a small but growing body of research that focuses on a range of small and nontraditional food retailer types, including corner stores, gas-marts, dollar stores and pharmacies ${ }^{(22-27)}$. As has been observed in previous studies with corner stores ${ }^{(6,8-11)}$, these stores attract loyal customers who are drawn there for convenience and make purchases daily or multiple times per week. As in previous corner store studies ${ }^{(6,7,9,10,38)}$, food and beverage purchases at small and non-traditional retailers are usually limited to a few dollars, for which a few low-nutrient, energy-dense products tend to be purchased. These stores serve customers from an array of racial/ethnic and socio-economic backgrounds, and commonly accept SNAP benefits for food purchases. Food categories for which purchasing was most common in the present study were sugar-sweetened beverages, grains, savoury snacks, candy, sweet baked goods and fats/sugars/condiments.

Overall diet quality scores (HEI-2010) for purchases at stores were low. The USDA has designated HEI scores below 51 as 'poor' ${ }^{\text {(43,54) }}$. With an average score of $36 \cdot 4$, the nutritional quality of foods purchased at most of these food stores is just over one-third of the optimal score of 100. For comparison, these scores are lower than those found in a study of menu offerings at eight leading national fast-food chain restaurants, where HEI-2010 
Table 3 Percentage of participants who purchased one or more serving of foods or beverages from a variety of food and beverage categories, overall and by store type, Minneapolis and St. Paul, MN, USA, July-November 2014

\begin{tabular}{|c|c|c|c|c|c|c|}
\hline Category & $\begin{array}{c}\text { All stores } \\
(n \text { 661) }\end{array}$ & $\begin{array}{l}\text { Corner store } \\
(n \text { 194) }\end{array}$ & $\begin{array}{c}\text { Gas-mart } \\
(n 268)\end{array}$ & $\begin{array}{l}\text { Dollar store } \\
\quad(n 67)\end{array}$ & $\begin{array}{c}\text { Pharmacy } \\
(n \text { 132) }\end{array}$ & $P^{\star}$ \\
\hline \multicolumn{7}{|l|}{ Foods } \\
\hline Grains & 18 & 22 & 18 & 25 & 11 & 0.03 \\
\hline Savoury snacks & 17 & 22 & 14 & 19 & 15 & $0 \cdot 10$ \\
\hline Candy & 15 & 9 & 10 & 28 & 28 & $<0.01$ \\
\hline Sweet baked goods & 13 & 7 & 18 & 15 & 12 & $<0.01$ \\
\hline Fats/sugars/condiments & 13 & 12 & 13 & 18 & 9 & 0.35 \\
\hline Processed meat & 7 & 7 & 9 & 4 & 4 & 0.19 \\
\hline Vegetables & 6 & 8 & 3 & 10 & 6 & 0.08 \\
\hline Red meat & 6 & 8 & 4 & 3 & 5 & 0.30 \\
\hline Cheese/yoghurt & 4 & 4 & 4 & 1 & 5 & 0.70 \\
\hline Poultry/fish & 4 & 6 & 3 & 4 & 2 & 0.22 \\
\hline Nuts/nut butter & 3 & 3 & 2 & 3 & 5 & 0.60 \\
\hline Fruit & 2 & 1 & 3 & 0 & 2 & 0.25 \\
\hline Ice cream & 2 & 2 & 1 & 1 & 3 & 0.53 \\
\hline Eggs & 2 & 2 & 3 & 0 & 2 & 0.66 \\
\hline Fried fruit/vegetable & 1 & 2 & 0.4 & 1 & 0 & 0.26 \\
\hline Miscellaneous & 1 & 1 & 0.4 & 4 & 2 & 0.05 \\
\hline Baby food & 0 & 0 & 0 & 0 & 0 & - \\
\hline Any food category $†$ & 64 & 61 & 63 & 73 & 66 & 0.33 \\
\hline \multicolumn{7}{|l|}{ Beverages } \\
\hline Sugar-sweetened & 46 & 47 & 46 & 58 & 36 & 0.03 \\
\hline Artificially sweetened & 8 & 7 & 10 & 1 & 11 & 0.06 \\
\hline Coffee/tea & 6 & 4 & 12 & 0 & 2 & $<0.01$ \\
\hline Milk & 5 & 3 & 5 & 3 & 7 & 0.43 \\
\hline Water (unsweetened) & 5 & 3 & 4 & 4 & 8 & 0.21 \\
\hline Fruit/vegetable juice & 3 & 3 & 3 & 1 & 3 & 0.93 \\
\hline Alcohol & 0.2 & 0 & 0.4 & 0 & 0 & 1.0 \\
\hline Any beverage category† & 67 & 64 & 72 & 66 & 60 & 0.06 \\
\hline
\end{tabular}

${ }^{*}$ Chi-square test except Fisher test when one or more cells has expected frequency $<5(\mathrm{df}=3$ ). $P \leq 0.05$ indicated in bold font.

†Purchased at least one serving in at least one of the product categories.

Table 4 Healthy Eating Index-2010 (HEI-2010) measures for aggregate purchases made by participants, overall and by store type, Minneapolis and St. Paul, MN, USA, July-November 2014

\begin{tabular}{|c|c|c|c|c|c|c|c|c|c|c|c|}
\hline & \multicolumn{2}{|c|}{ All stores (n 105) } & \multicolumn{2}{|c|}{ Corner store ( $n$ 39) } & \multicolumn{2}{|c|}{ Gas-mart ( $n$ 37) } & \multicolumn{2}{|c|}{ Dollar store $(n 9)$} & \multicolumn{2}{|c|}{ Pharmacy (n 20) } & \multirow[b]{2}{*}{$P^{\star}$} \\
\hline & Mean & SD & Mean & SD & Mean & SD & Mean & SD & Mean & SD & \\
\hline $\begin{array}{l}\text { HEI total (possible range: } 0-100 \text { ) } \\
\text { HEI sub-components }\end{array}$ & $36 \cdot 4$ & $12 \cdot 5$ & $37 \cdot 2$ & $10 \cdot 6$ & $34 \cdot 6$ & $14 \cdot 1$ & $32 \cdot 9$ & $9 \cdot 5$ & 39.9 & $13 \cdot 8$ & 0.37 \\
\hline Total vegetables $(0-5)$ & 0.5 & $1 \cdot 1$ & 0.8 & 1.6 & 0.2 & 0.5 & 0.9 & 1.0 & 0.4 & 0.6 & 0.09 \\
\hline Greens \& beans $(0-5)$ & 0.2 & 0.9 & 0.3 & $1 \cdot 1$ & 0.2 & 0.9 & 0.02 & 0.05 & 0 & 0 & 0.68 \\
\hline Total fruit $(0-5)$ & 0.5 & 1.3 & 0.2 & 0.8 & $0 . \overline{6}$ & 1.4 & 0.6 & 1.6 & 0.7 & 1.6 & 0.42 \\
\hline Whole fruit $(0-5)$ & 0.2 & 0.8 & 0.1 & 0.3 & 0.4 & $1 \cdot 1$ & 0 & 0 & 0.2 & 0.7 & 0.17 \\
\hline Whole grains $(0-10)$ & $2 \cdot 6$ & $3 \cdot 7$ & 3.0 & $3 \cdot 8$ & $2 \cdot 3$ & 3.8 & 3.4 & 3.9 & 1.8 & $3 \cdot 1$ & 0.56 \\
\hline Dairy $(0-10)$ & $2 \cdot 7$ & 3.6 & 1.8 & $3 \cdot 3$ & $3 \cdot 0$ & 3.7 & $1 \cdot 7$ & 3.3 & 4.0 & 3.7 & 0.11 \\
\hline Total protein foods $(0-5)$ & 1.8 & $2 \cdot 0$ & 1.9 & $2 \cdot 1$ & $2 \cdot 0$ & 1.9 & 0.9 & 1.6 & 1.9 & $2 \cdot 0$ & 0.49 \\
\hline Seafood \& plant proteins $(0-5)$ & 0.9 & 1.8 & 0.8 & 1.6 & 0.8 & 1.7 & 0.9 & 1.8 & 1.4 & $2 \cdot 2$ & 0.57 \\
\hline Fatty acids $(0-10)$ & $5 \cdot 3$ & 4.2 & 6.4 & 4.3 & 4.6 & $4 \cdot 1$ & $6 \cdot 3$ & 3.2 & 4.2 & 4.2 & 0.15 \\
\hline Sodium (0-10) & 7.6 & 3.5 & $6 \cdot 7$ & $4 \cdot 1$ & $8 \cdot 1$ & 3.0 & $7 \cdot 1$ & $4 \cdot 1$ & $8 \cdot 4$ & $2 \cdot 8$ & 0.20 \\
\hline Refined grains $(0-10)$ & $7 \cdot 2$ & 3.6 & $7 \cdot 0$ & 3.9 & 7.4 & 3.2 & 5.9 & 4.7 & $7 \cdot 8$ & $3 \cdot 2$ & 0.60 \\
\hline Empty calories $(0-20)$ & $7 \cdot 1$ & $7 \cdot 4$ & 8.5 & 8.0 & 4.9 & $6 \cdot 1$ & $5 \cdot 2$ & $6 \cdot 4$ & 9.1 & 7.9 & 0.08 \\
\hline
\end{tabular}

*General linear model (SAS PROC GLM).

scores ranged from 38 to $56^{(48)}$. A large-scale study of the diet quality of household grocery purchases conducted by the USDA demonstrated average HEI-2005 scores of $56 \cdot 4^{(50)}$. Findings from the current study indicate that there is considerable room for improvement in the nutritional quality of purchases at small and non-traditional food retailers. These stores contribute to an abundance of poorquality food exposures encountered by US adults, who demonstrate consistent suboptimal diet quality scores on a population level $^{(44,55)}$. Improving overall diet quality in the US population will require coordinated efforts throughout all sectors of food retail to improve healthy food availability, purchasing and consumption.

Customers at small and non-traditional food stores tend to purchase foods and beverages with a high yield of energy per dollar ${ }^{(10)}$. While the purchasing of less healthy 
food items is not unique to small and non-traditional stores, evidence suggests that indicators of nutritional quality of purchases may be consistently lower in these stores $^{(27)}$. This appears particularly true at dollar stores, where customers spent a median of \$US 2.89 for a median of $5302 \mathrm{~kJ}(1266 \mathrm{kcal})$ - more than twice as many kilojoules as at other store types. Unconventional pricing and packaging at dollar stores could result in a higher yield of energy purchased. As one example of the potential influence of package sizes, in our sample, honey buns were purchased at a dollar store in a package of $\sim 300 \mathrm{~g}$ $(10.5 \mathrm{oz})$ for $\$$ US $1 \cdot 00$. The three other customers who purchased honey buns (at a corner store, a gas-mart and a pharmacy) purchased them in packages of $\sim 85 \mathrm{~g}(3 \mathrm{oz})$ for $\$$ US 0.50. Thus, a customer who wanted to buy honey buns would end up with an excess of $3765 \mathrm{~kJ}$ ( $899 \mathrm{kcal}$ ) for \$US 0.50 more in a dollar store compared with the other three store types. Not all items at a dollar store are in sold in large package sizes, but our results suggest that, on average, dollar stores' packaging may result in particularly high number of kilojoules per dollar.

Overall, in addition to total energy, the nutritional quality of customer purchases at dollar stores was poor. Dollar store customers were the most likely to purchase sugar-sweetened beverages and candy, and dollar store purchases were the most sugar-laden; purchases contained a median of $53 \%$ of energy from added sugar. The 2015-2020 Dietary Guidelines for Americans recommend limiting the consumption of added sugar to less than $10 \%$ of energy ${ }^{(33)}$. However, even at other corner stores, gas-marts and pharmacies in our sample, purchases contained a proportion of added sugar that far surpassed these recommendations.

Purchases of healthier foods, like fruits, vegetables and other staple food items, were rare at all store types. To some extent, customer purchasing decisions may be driven by a lack of availability of healthy options at these corner stores. Two previous studies on the availability of healthy items in a similar sample of corner stores, gas-marts, dollar stores and pharmacies, conducted in early 2014 in Minnesota, demonstrated the lack of healthy options in these types of food retailers ${ }^{(24,25)}$. For example, in most dollar stores and pharmacies, canned fruits and vegetables were the only option for produce ${ }^{(24)}$. Wholegrain options were rare, with only one-quarter of the SNAP-authorized stores in the sample stocking wholegrain-rich products, such as wholegrain-rich bread, tortillas or brown rice ${ }^{(25)}$. A recent study of corner store purchases in New York City by Ruff et al. demonstrated that healthy food availability may be related to both healthy and less healthy food purchases; the more fresh produce that was available, the more produce was purchased and the less sugar-sweetened beverages were purchased $^{(9)}$. Upcoming requirement changes to SNAPauthorized stores may increase the number of varieties and food groups that stores will carry. However, it is difficult to surmise the impact of these requirements on customer purchases. If food purchases were driven entirely by availability, in our study we might have expected even more purchasing of healthy foods, as well as more variation in healthy food purchases across store types. For example, previous analyses in the study area suggest that most corner stores stock at least one kind of fresh fruit or vegetable (over $60 \%)^{(24)}$, yet only $1 \%$ of customers from corner stores in our sample bought fruit and $8 \%$ bought vegetables. Purchases of healthy and other staple foods were similarly low across all store types, even though stores likely carry frozen and canned fruits and vegetables if not fresh ${ }^{(24)}$.

Corner stores have increasingly been targets for interventions, given their presence in lower-income neighbourhoods, the frequency with which customers visit them and the poor nutritional quality of customers' purchases $^{(1-3)}$. Most intervention efforts have focused on increasing the availability of healthy options, as have policy efforts such as the Minneapolis Staple Foods Ordinance and the 2014 Farm Bill. Improvements in product assortment are certainly a necessary condition for improving the nutritional quality of customers' purchases. However, addressing healthy food availability alone may not be sufficient to improve the nutritional quality of purchases without also addressing other factors that drive customer decisions. An intervention in small food stores in Philadelphia showed that, even after intervention efforts to improve healthy food supply in the store, there was no improvement in the nutritional quality of purchases; the authors suggest the need for marketing, education and price-related strategies to complement improving inventory quality ${ }^{(38)}$. Increases in customer supply are not likely to be sustainable without a corresponding increase in customer demand ${ }^{(3)}$. Indeed, small food store interventions that have included efforts to increase demand for healthy foods, community engagement efforts, and pricing and marketing strategies have demonstrated more promise $e^{(3,11,36,37)}$. A recent expert panel on small and non-traditional food stores made specific recommendations for both availability and marketing of healthy items ${ }^{(56)}$. The role of food marketing and promotions - such as the presence of impulse buys by the checkout counter - could be particularly relevant in gas-marts, dollar stores and pharmacies, where customers may or may not intend to buy any food or beverage when they enter the store. Less healthful products are ubiquitous near the checkout counter in these types of establishments, while healthful options are rarer (TL Barnes, JE Pelletier, DJ Erickson et al., unpublished results).

Our study has several limitations that should be acknowledged. Data were collected in a limited store sample that excluded large grocery stores and WIC retailers. Moreover, customers obtain food from many sources and the study did not quantify what proportion of customers' daily or weekly shopping the purchase 
represented. It is, therefore, not possible to draw conclusions about how much each purchase contributed to customers' total food purchasing, total diet or the overall quality of their diet. Analyses considered only what customers purchased (the demand side) and not what was available in the store (supply side). Furthermore, it is unknown whether the purchase was intended to be consumed solely by the respondent ( $v$. shared with others) and whether the entire purchase was actually consumed (v. wasted).

The overall participation rate of $35 \%$ in the study is perhaps not unexpected. Most studies using customer intercept interviews in small food stores have not reported participation rates or information on nonparticipants $^{(6-8,15)}$. Our rate is slightly higher than the $32.9 \%$ participation rate reported by Ruff et $\mathrm{al}$. in a recent study that used a similar methodology in small, urban food stores $^{(9)}$. A higher participation rate (53-63\%) was found by Dannefer et $a l^{(11)}$, but customer interviews in that study were conducted only in a small subset of eligible stores selected 'on the basis of the owners' willingness' to participate, which may have offered a setting particularly amenable to recruitment. In the current study, participation was lowest in pharmacies (27\%) and gas-marts (32\%). In these store types in particular, customers may have stopped in for a brief errand and may have had less time than customers at corner stores or dollar stores. Differential response rates probably did not lead to meaningful bias in the overall findings in the current study, especially given that pharmacies had the highest HEI-2010 scores but gas-marts had the second-lowest. A recent analysis of the impact of differences in organizational response rates on performance outcomes concluded that differential response rates did not result in substantial bias in performance results or interpretation, even though outcomes were somewhat worse at organizations with low response rates ${ }^{(57)}$. As a final consideration, anyone exiting stores who carried a bag and did not engage with data collectors was marked as a refusal, even though they may have been ineligible. This misclassification may have resulted in an artificially low response rate, particularly in pharmacies, where many non-consumable purchases are made and bagged.

It must be noted that the higher participation rate among Black/African American customers could have biased results if the nutritional quality and content of customers' purchases was lower or higher among Blacks/African Americans. For example, if Black/African American participants were more likely to participate and also more likely to purchase sugar-sweetened beverages, then the true average for HEI-2010 scores may be higher, and the true energy and sugar content of purchases could be lower. Participation rates among Blacks/African Americans were, however, stable across store type, so the potential bias would likely not differ by store type. More importantly, our results, taken in conjunction with the broader body of small and non-traditional food store literature, demonstrate a consistent and robust pattern of purchases with a high energy-to-dollar ratio, high energy density and low overall nutritional quality that is unlikely to be explained by selection bias in the current study.

Thus, the study contributes to the literature on customer purchases in small, urban food retailers, particularly at understudied store types, such as gas-marts, pharmacies and dollar stores. The study also has a number of other strengths. We captured data on customer purchases via direct observation rather than self-report. Our nutrient analysis also allowed us to calculate an HEI-2010 score for purchases at each store. The present study is among the first to report HEI-2010 scores using food purchase data and these scores can be directly compared with purchases from other food sources or specific food environments.

Overall, our results confirm the findings from other corner store studies conducted in other regions of the USA, while also including an understudied sample of customers from gas-marts, dollar stores and pharmacies. These stores, many of which accept SNAP benefits, are a regular source of low-nutrient, energy-dense foods for many customers on a daily basis. In the future, it will be important to expand the reach of evaluations and interventions to include these, as well as other small and non-traditional and less visible sources of food ${ }^{(58,59)}$ in the community environment. Our findings support the need to encourage healthy food purchases at small and nontraditional retailers, particularly in light of upcoming policy changes that may result in healthier options within the store.

\section{Acknowledgements}

Acknowledgements: The authors would like to acknowledge Kristen Klingler and Nora Gordon at the Minneapolis Health Department for their support and expertise working with local small food stores. They would also like to acknowledge the large data acquisition and data management team, most especially Stacey Moe and Pamela Carr-Manthe. Finally, they thank the participants of this study. Financial support: This research was supported by the National Institute of Diabetes and Digestive and Kidney Diseases of the National Institutes of Health (M.N.L., grant number R01DK104348) and the Global Obesity Prevention Center (GOPC) at Johns Hopkins, which is supported by the Eunice Kennedy Shriver National Institute of Child Health and Human Development and the Office of the Director, National Institutes of Health (M.N.L., grant number U54HD070725). Support for the lead author was provided by the National Cancer Institute, Cancer Related Health Disparities Education and Career Development Program (C.E.C., grant number R25CA163184). Data management was supported by the 
National Center for Advancing Translational Sciences (NCATS), National Institutes of Health (grant number UL1TR000114). The content is solely the responsibility of the authors and does not necessarily represent the official views of the National Institutes of Health. Funding agencies had no role in the design, analysis or writing of this article. Conflict of interest: The authors do not declare any conflicts of interest. Authorship: C.E.C. was responsible for formulating the research questions and leading manuscript writing, and also supported carrying out the study from which these data originated. K.L. conducted the data analysis and contributed to writing/revision of the manuscript. J.E.P. assisted with data management and data analysis, contributed to writing/revision of the manuscript, and supported carrying out the study from which these data originated. T.L.B. assisted with variable creation, including the HEI-2010, and contributed to writing and revising the manuscript. L.H. oversaw the nutrient analysis, assisted in interpreting results, and made contributions to writing and revising the manuscript. D.J.E. guided and provided feedback on the analysis, assisted in interpreting results, and contributed to writing/revision of the manuscript. M.N.L. was responsible for leading the overall study from which these data originated, including conception/ design, funding acquisition and implementation; and gave feedback on analyses and writing/revision of the manuscript. Etbics of buman subject participation: This study was conducted according to the guidelines laid down in the Declaration of Helsinki and all procedures involving human subjects/patients were approved by the University of Minnesota. Verbal informed consent was obtained from all participants. Verbal consent was witnessed and formally recorded.

\section{Supplementary material}

To view supplementary material for this article, please visit http://dx.doi.org/10.1017/S1368980016002524

\section{References}

1. D'Angelo H, Suratkar S, Song H-J et al. (2011) Access to food source and food source use are associated with healthy and unhealthy food-purchasing behaviours among lowincome African-American adults in Baltimore City. Public Health Nutr 14, 1632-1639.

2. Bodor JN, Ulmer VM, Dunaway LF et al. (2010) The rationale behind small food store interventions in low-income urban neighborhoods: insights from New Orleans. J Nutr 140, 1185-1188.

3. Gittelsohn J, Rowan M \& Gadhoke P (2012) Interventions in small food stores to change the food environment, improve diet, and reduce risk of chronic disease. Prev Chronic Dis 9. E59.

4. Powell L, Slater S, Mirtcheva D et al. (2007) Food store availability and neighborhood characteristics in the United States. Prev Med 44, 189-195.
5. Cannuscio CC, Weiss EE \& Asch DA (2010) The contribution of urban foodways to health disparities. J Urban Health $\mathbf{8 7}$, 381-393.

6. Kiszko K, Cantor J, Abrams C et al. (2015) Corner store purchases in a low-income urban community in NYC. J Community Health 40, 1084-1090.

7. Lent MR, Veur SV, Mallya G et al. (2015) Corner store purchases made by adults, adolescents and children: items, nutritional characteristics and amount spent. Public Health Nutr 18, 1706-1712.

8. Pitts SBJ, Bringolf KR, Lawton KK et al. (2013) Formative evaluation for a healthy corner store initiative in Pitt County, North Carolina: assessing the rural food environment, part 1. Prev Chronic Dis 10, E121.

9. Ruff RR, Akhund A \& Adjoian T (2016) Small convenience stores and the local food environment: an analysis of resident shopping behavior using multilevel modeling. Am J Health Promot 30, 172-180.

10. Borradaile KE, Sherman S, Vander Veur SS et al. (2009) Snacking in children: the role of urban corner stores. Pediatrics 124, 1293-1298.

11. Dannefer R, Williams DA, Baronberg S et al. (2012) Healthy bodegas: increasing and promoting healthy foods at corner stores in New York City. Am J Public Health 102, e27-e31.

12. Cavanaugh E, Mallya G, Brensinger $C$ et al. (2013) Nutrition environments in corner stores in Philadelphia. Prev Med 56, 149-151.

13. Laska MN, Borradaile KE, Tester J et al. (2010) Healthy food availability in small urban food stores: a comparison of four US cities. Public Health Nutr 13, 1031-1035.

14. Gittelsohn J \& Kumar MB (2007) Preventing childhood obesity and diabetes: is it time to move out of the school? Pediatr Diabetes 8, 55-69.

15. O'Malley K, Gustat J, Rice J et al. (2013) Feasibility of increasing access to healthy foods in neighborhood corner stores. J Community Health 38, 741-749.

16. Lent MR, Vander Veur SS, McCoy TA et al. (2014) A randomized controlled study of a healthy corner store initiative on the purchases of urban, low-income youth. Obesity (Silver Spring) 22, 2494-2500.

17. Laska MN, Hearst MO, Forsyth A et al. (2010) Neighbourhood food environments: are they associated with adolescent dietary intake, food purchases and weight status? Public Health Nutr 13, 1757-1763.

18. Morland K, Roux A \& Wing S (2006) Supermarkets, other food stores, and obesity: the atherosclerosis risk in communities study. Am J Prev Med 30, 333-339.

19. Morland K \& Evenson K (2009) Obesity prevalence and the local food environment. Health Place 15, 491-495.

20. Wall MM, Larson NI, Forsyth A et al. (2012) Patterns of obesogenic neighborhood features and adolescent weight a comparison of statistical approaches. Am J Prev Med 42, E65-E75.

21. Whitehouse A, Simon A, French SA et al. (2012) Availability of snacks, candy and beverages in hospital, community clinic and commercial pharmacies. Public Health Nutr 15, 1117-1123.

22. Adjoian T, Dannefer R, Sacks R et al. (2014) Comparing sugary drinks in the food retail environment in six NYC neighborhoods. J Community Health 39, 327-335.

23. Farley TA, Baker ET, Futrell L et al. (2010) The ubiquity of energy-dense snack foods: a national multicity study. Am J Public Health 100, 306-311.

24. Caspi CE, Pelletier JE, Harnack L et al. (2016) Differences in healthy food supply and stocking practices between small grocery stores, gas-marts, pharmacies and dollar stores. Public Health Nutr 19, 540-547.

25. Laska MN, Caspi CE, Pelletier JE et al. (2015) Lack of healthy food in small-size to mid-size retailers participating in the Supplemental Nutrition Assistance Program, MinneapolisSt. Paul, Minnesota, 2014. Prev Chronic Dis 12, E135. 
26. Stern D, Robinson WR, Ng SW et al. (2015) US household food shopping patterns: dynamic shifts since 2000 and socioeconomic predictors. Health Aff (Millwood) 34, $1840-1848$

27. Stern D, Ng SW \& Popkin BM (2016) The nutrient content of US household food purchases by store type. Am J Prev Med 50, 180-190.

28. Jopson B (2011) Bi-Lo to take Winn-Dixie private in $\$ 560 \mathrm{~m}$ deal. Financial Times, 19 December 2011; available at http://www.ft.com/cms/s/0/ae68dd52-2a4c-11e1-8f0400144feabdc0.html\#axzz4IpJlh3c1（accessed September 2016).

29. Wood S (2013) Revisiting the US food retail consolidation wave: regulation, market power and spatial outcomes. J Econ Geogr 13, 299-326.

30. Euromonitor International (2014) Trends in US Grocery Retailing. London: Euromonitor International.

31. Martinez SW (2007) The US Food Marketing System: Recent Developments, 1997-2006. Economic Research Report no. ERR-42. Washington, DC: US Department of Agriculture, Economic Research Service.

32. Gantner LA, Olson CM, Frongillo EA et al. (2011) Prevalence of nontraditional food stores and distance to healthy foods in a rural food environment. J Hunger Environ Nutr $\mathbf{6}$, 279-293.

33. US Department of Health and Human Services \& US Department of Agriculture (2015) Dietary Guidelines for Americans 2015-2020, 8th ed. http://health.gov/diet aryguidelines/2015/guidelines/ (accessed January 2016).

34. Castner L \& Henke J (2011) Benefit Redemption Patterns in the Supplemental Nutrition Assistance Program. Alexandria, VA: US Department of Agriculture, Food and Nutrition Service.

35. Shannon J (2014) What does SNAP benefit usage tell us about food access in low-income neighborhoods? Soc Sci Med 1982 107, 89-99.

36. Gittelsohn J, Song H-J, Suratkar S et al. (2010) An urban food store intervention positively affects food-related psychosocial variables and food behaviors. Health Educ Behav 37, 390-402.

37. Song H-J, Gittelsohn J, Kim M et al. (2009) A corner store intervention in a low-income urban community is associated with increased availability and sales of some healthy foods. Public Health Nutr 12, 2060-2067.

38. Lawman HG, Veur SV, Mallya G et al. (2015) Changes in quantity, spending, and nutritional characteristics of adult, adolescent and child urban corner store purchases after an environmental intervention. Prev Med 74, 81-85.

39. US Government, 113th Congress (2014) Public Law 113-79 - Feb 7, 2014. 128 Stat. 649. https://www.gpo. gov/fdsys/pkg/PLAW-113publ79/pdf/PLAW-113publ79.pdf (accessed July 2016).

40. Minneapolis Health Department (2016) Minneapolis Staple Foods Ordinance. http://www.minneapolismn.gov/health/ living/eating/staple-foods (accessed April 2016).

41. Guenther PM, Reedy J, Krebs-Smith SM et al. (2008) Evaluation of the Healthy Eating Index-2005. J Am Diet Assoc 108, 1854-1864.

42. Guenther PM, Reedy J \& Krebs-Smith SM (2008) Development of the Healthy Eating Index-2005. J Am Diet Assoc 108, 1896-1901

43. US Department of Agriculture, Center for Nutrition Policy and Promotion (2016) Healthy Eating Index. http://www.cnpp. usda.gov/healthyeatingindex.htm (accessed April 2016).
44. Guenther PM, Casavale KO, Reedy J et al. (2013) Update of the Healthy Eating Index: HEI-2010. J Acad Nutr Diet 113, 569-580.

45. Reedy J, Krebs-Smith SM \& Bosire C (2010) Evaluating the food environment: application of the Healthy Eating Index2005. Am J Prev Med 38, 465-471.

46. Krebs-Smith SM, Reedy J \& Bosire C (2010) Healthfulness of the US food supply: little improvement despite decades of dietary guidance. Am J Prev Med 38, 472-477.

47. Miller PE, Reedy J, Kirkpatrick SI et al. (2015) The United States food supply is not consistent with dietary guidance: evidence from an evaluation using the Healthy Eating Index-2010. J Acad Nutr Diet 115, 95-100.

48. Hearst MO, Harnack LJ, Bauer KW et al. (2013) Nutritional quality at eight US fast-food chains: 14-year trends. Am J Prev Med 44, 589-594.

49. Jahns L, Scheett AJ, Johnson LK et al. (2016) Diet quality of items advertised in supermarket sales circulars compared to diets of the US population, as assessed by the Healthy Eating Index-2010. J Acad Nutr Diet 116, 115.e1-122.e1.

50. Volpe R \& Okrent A (2012) Assessing the Healthfulness of Consumers' Grocery Purchases. Economic Information Bulletin no. EIB-102. Washington, DC: US Department of Agriculture, Economic Research Service.

51. Caspi C, Friebur R, Davey C et al. (2016) Results of a pilot intervention to improve dietary outcomes among adults experiencing food insecurity. J Hunger Environ Nutr (Epublication ahead of print version).

52. Eicher-Miller HA, Khanna N, Boushey CJ et al. (2016) Temporal dietary patterns derived among the adult participants of the National Health and Nutrition Examination Survey 1999-2004 are associated with diet quality. J Acad Nutr Diet 116, 283-291.

53. Hiza HAB, Casavale KO, Guenther PM et al. (2013) Diet quality of Americans differs by age, sex, race/ethnicity, income, and education level. I Acad Nutr Diet 113, 297-306.

54. Guenther PM, Reedy J, Krebs-Smith SM et al. (2007) Development and Evaluation of the Healthy Eating Index-2005: Technical Report. Alexandria, VA: US Department of Agriculture, Center for Nutrition Policy and Promotion.

55. Wang DD, Leung CW, Li Y et al. (2014) Trends in dietary quality among adults in the United States, 1999 through 2010. JAMA Intern Med 174, 1587-1595.

56. Laska MN \& Pelletier JE (2016) Minimum Stocking Levels and Marketing Strategies of Healthful Foods for Small Retail Food Stores. Minneapolis, MN: Healthy Eating Research.

57. Saunders CL, Elliott MN, Lyratzopoulos G et al. (2016) Do differential response rates to patient surveys between organizations lead to unfair performance comparisons?: evidence from the English Cancer Patient Experience Survey. Med Care 54, 45-54.

58. Wright J, Kamp E, White M et al. (2015) Food at checkouts in non-food stores: a cross-sectional study of a large indoor shopping mall. Public Health Nutr 18, 2786-2793.

59. Lucan SC, Seitchick J, Yoon DH et al. (2015) Unexpected businesses may improve food environments in urban neighborhoods. Presented at the American Public Health Association Annual Meeting, Chicago, IL, 2 November 2015. 